\title{
Analysis on Factors Affecting the Self-Repair Capability of SMA Wire Concrete Beam
}

\author{
Li Sun, Dezhi Liang, Qianqian Gao, and Jianhong Zhou \\ School of Civil Engineering, Shenyang Jianzhu University, Shenyang 110168, China \\ Correspondence should be addressed to Li Sun; sunli2009@163.com
}

Received 24 September 2013; Accepted 21 November 2013

Academic Editor: Xiao-Wei Ye

Copyright (C) 2013 Li Sun et al. This is an open access article distributed under the Creative Commons Attribution License, which permits unrestricted use, distribution, and reproduction in any medium, provided the original work is properly cited.

Crack expansion of concrete is the initial damage stage of structures, which may cause greater damage to structures subject to longterm loads or under extreme conditions. In recent years, the application of intelligent materials to crack self-repair has become a hotspot among researchers. In order to study the influence of factors on the self-repair capability of shape memory alloy (SMA) wire concrete beam, both theoretical and experimental methods were employed for analysis. For the convenience of experiment, composite materials (epoxy cement mortar and silicone polymer clay) instead of concrete were used. The SMA wires were externally installed on and internally embedded in epoxy resin cement mortar beams and silicone polymer clay beams. Comparison of crack repair situation between two installation methods turns out that both methods possess their own advantages and disadvantages and should be employed according to the actual situation. The influence of unbonded length on the self-repair capability of embedded type SMA wire beams and the necessary minimum unbonded length to achieve self-repair function were studied. The results state clearly that the longer the unbonded length is, the better the crack repair situation is.

\section{Introduction}

SMA [1] is a kind of material with shape memory function realized by phase transition which is induced by stress and temperature. Plastic deformation will be generated when SMA which is shaped under a high temperature is placed in a low or room temperature environment. When the ambient temperature rises to the critical temperature, that is, phase transition temperature, the deformation disappears and SMA can be recovered to the initial design state. In this process, the displacement or stress in SMA is the function of temperature. The phenomenon that deformation disappears with the increase of temperature and the shape recovers is called the shape memory effect.

For concrete structures which are prone to crack, the shape memory effect of SMA can be employed to reinforce or repair the cracked structures. One way is to fix SMA material on the structure, and the other is to embed SMA material as reinforcement in the structure, reserving a certain unbonded length.

Many researchers have done much work in this field. By fixing SMA wires on concrete beams, Luo [2] investigated the driving performance and the repair performance of SMA wires. By embedding prestressed SMA wires in concrete beams, He et al. [3] studied the response of the beams under static loading and constant impact loading and the effects of the SMA wires on the repair of cracks. Embedding SMA wires in composite components, Tao [4] tested the repair function of restoring force induced by heating in SMA wires. Maji and Negret [5] embedded SMA sterepsinema in mortar trabeculae and loaded used three-point bending test until visible cracks appeared. Then the SMA sterepsinema was heated by electricity. After a period of time, the visible crack fully recovers, which turns out that the SMA sterepsinema has a great driving function.

Shi Yan et al. [6] applied the shape memory effect of the SMA to make intelligent reinforced concrete continuous beams. The principle of self-repairing property and the factors affecting self-repairing property were experimentally studied. It turns out that deformation and crack width can be significantly decreased by the heated SMA bars. The driving effect can be enhanced by increasing the total cross-section area of the SMA bars or the reinforcement ration of the SMA bars. Li et al. [7-9] investigated SMA for intelligently 
TABLE 1: Properties of tested beams.

\begin{tabular}{|c|c|c|c|c|c|}
\hline Beam no. & $\begin{array}{c}\text { Specimen } \\
\text { dimension }(\mathrm{mm})\end{array}$ & $\begin{array}{l}\text { Unbonded length } \\
\text { of beams } l_{1}(\mathrm{~mm})\end{array}$ & $\begin{array}{l}\text { Diameter of } \mathrm{Ni}-\mathrm{Ti} \\
\text { alloy wire }(\mathrm{mm})\end{array}$ & $\begin{array}{l}\text { Thickness of } \\
\text { protective layer } \\
(\mathrm{mm})\end{array}$ & Type of material \\
\hline Al-1 & $20 \times 30 \times 200$ & 0 & 0.5 & 5 & $\begin{array}{l}\text { Mixtures of epoxy resins and } \\
\text { cement mortars }\end{array}$ \\
\hline $\mathrm{Al}-2$ & $20 \times 30 \times 200$ & 10 & 0.5 & 5 & $\begin{array}{l}\text { Mixtures of epoxy resins and } \\
\text { cement mortars }\end{array}$ \\
\hline Al-3 & $20 \times 30 \times 200$ & 40 & 0.5 & 5 & $\begin{array}{l}\text { Mixtures of epoxy resins and } \\
\text { cement mortars }\end{array}$ \\
\hline $\mathrm{Al}-4$ & $20 \times 30 \times 200$ & - & - & - & $\begin{array}{l}\text { Mixtures of epoxy resins and } \\
\text { cement mortars }\end{array}$ \\
\hline Bl-1 & $20 \times 30 \times 200$ & 0 & 0.5 & 5 & Mixtures of silicones and clays \\
\hline Bl-2 & $20 \times 30 \times 200$ & 10 & 0.5 & 5 & Mixtures of silicones and clays \\
\hline Bl-3 & $20 \times 30 \times 200$ & 40 & 0.5 & 5 & Mixtures of silicones and clays \\
\hline $\mathrm{Bl}-4$ & $20 \times 30 \times 200$ & - & - & - & Mixtures of silicones and clays \\
\hline
\end{tabular}

Note: "-" indicates that there is no SMA wire in the beam.

self-repairing of concrete structures. The results present that the heating method is an important influencing factor in the restoring force of SMA.

However, no further research has been done by scholars on comparison of the advantages and disadvantages between the two installation methods mentioned above and the influence of unbonded length on the repair capacity of internally embedded installation method. This is just the main subject which the paper focuses on.

\section{Experiment Scheme}

For the convenience of experiment, the tested beams are made from composite materials instead of concrete. Seven groups of beams numbered as Al-1, Al-2, Al-3, Al-4, Bl-1, $\mathrm{Bl}-2$, and $\mathrm{Bl}-3$ are made. Beams from $\mathrm{Al}-1$ to $\mathrm{Al}-4$ are made from epoxy resins and cement mortars and the rest are made from silicones and clays. The dimension of beams and SMA alloy wires and the unbonded length of SMA alloy wires are tabulated in Table 1.

The experiment was completed in the mechanical laboratory of Shenyang Jianzhu University and a universal testing machine was used as the loading device. Firstly, three-point bending test was employed to load each beam until visible cracks appeared. The cracked beams were repaired in two ways. One way was to internally embed SMA wires in the structure with reserving a certain unbonded length, as shown in Figure 1(a). The power was connected to the beam at both ends of the alloy wire for heating the alloy wire, so that the cracks were repaired by force generated by heated alloy wire. This method was applied to beams numbered as Al-1, Al-2, Al-3, BL-1, Bl-2, and Bl-3, in which the unbonded lengths of SMA wires were different. The other way was to externally install Ni-Ti alloy wires on the surface of beam numbered as Al-4, as shown in Figure 1(b). The power was connected to the beam at both ends of the alloy wire for heating the alloy wire, so that the cracks were repaired by force generated by heated alloy wire. According to crack recovery situation, current strength, and power-on time, the advantages and disadvantages of the two installation methods mentioned above were compared and the influence of unbonded length of the internally embedded installation repair method was analysed.

\section{Factors Affecting the Self-Repair Capability of Polymer Beams}

3.1. Influence of Installation Method. As can be seen from Figure 1, different bending moment results from different acting location of the restoring force generated by the alloy wire using the two methods. Assume that the central axis is in the middle of the beam, and mechanics is analyzed based on the theory of the concrete structure.

(1) Force analysis of internal embedded repair method:

$$
\begin{gathered}
M_{m}=F\left(\frac{h}{2}-c\right), \\
F=\sigma S
\end{gathered}
$$

where $M_{m}$ indicates the restoring bending moment, $F$ is the restoring force, $h$ is the height of beam, $c$ is the thickness of the protective layer, $\sigma$ is restoring stress in the SMA wire, and $S$ is the cross sectional area of the SMA wire.

(2) Force analysis of external installation repair method:

$$
M_{f}=F\left(\frac{h}{2}+x\right),
$$

where $x$ indicates the distance from the SMA wire to the bottom of the beam.

Comparing (1) with (3), $M_{m}<M_{f}$ if the restoring force $F$ is the same. In view of this, external installed SMA wire is more favorable in beam crack closure.

Experiment configurations of beam crack closure using different installation methods of SMA wires are shown in Figures 2 and 3. Bending moments in two cases are different due to different acting points of the restoring forces $F$ generated 


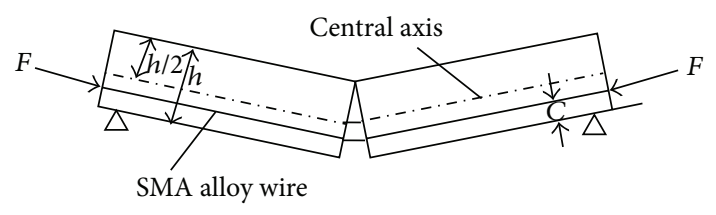

(a) Internal embedment repair method

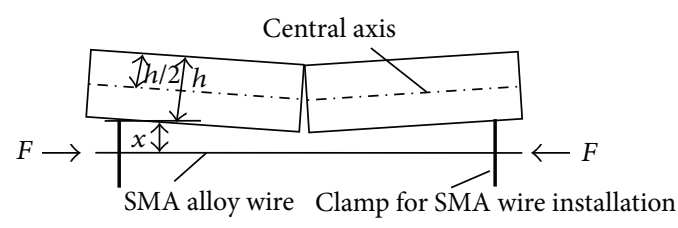

(b) External installation repair method

FIGURE 1: Methods of repairing beam cracks.

TABLE 2: The basic situations in beam crack closure processes.

\begin{tabular}{lccccc}
\hline Beam no. & $\begin{array}{c}\text { Crack width before } \\
\text { power-on } w(\mathrm{~mm})\end{array}$ & $\begin{array}{c}\text { Crack recovery value } \\
\Delta w(\mathrm{~mm})\end{array}$ & $\begin{array}{c}\text { Crack recovery degree } \\
\eta(\%)\end{array}$ & $\begin{array}{c}\text { Current intensity } \\
I(\mathrm{~A})\end{array}$ & Power-on time $t(\mathrm{~s})$ \\
\hline Al-1 & 3.075 & 1.11 & 36.1 & 3 & 30 \\
Al-4 & 2.212 & 2.186 & 98.8 & 2.8 & 20 \\
\hline
\end{tabular}

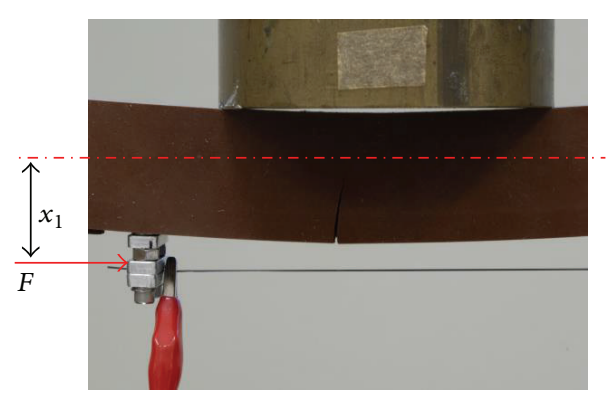

FIGURE 2: External installed SMA wires.

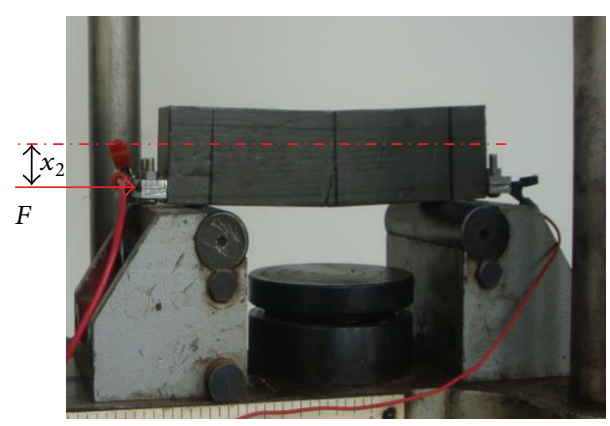

FIGURE 3: Internal embedded SMA wires.

by the alloy wires. If restoring forces $F$ are the same, we have $x_{1}>x_{2}$ according to (1) and (3). Therefore, the bending moment in Figure 2 is larger than that in Figure 3. The crack can be more easily recovered using external installed SMA wire (as shown in Figure 2), and less energy is consumed. Without regard to any other factor except for installation method, comparison between two installation methods is tabulated in Table 2.

As can be seen from Table 2, external installed SMA wire not only needs smaller current intensity and less power-on time, but also recovers much more than internal embedded SMA wire does.

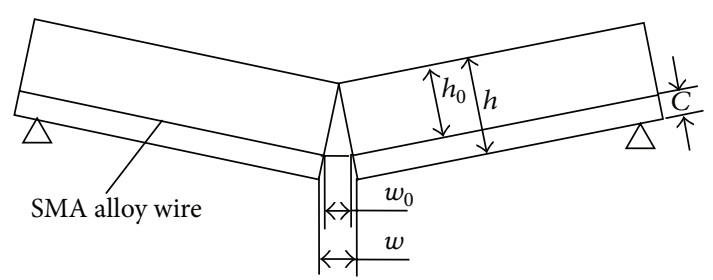

FIgURE 4: Schematic diagram of internally embedded SMA wires for crack closure.

However, the installation process of external installation method is more complicated. There are not only preembedded parts in the structure, but also installation devices externally erected outside the structure. The cost of external installation method is much higher than that of internally embedded method. But SMA wires which are used in external installation method are reusable and have lower cost and higher activation force. Therefore, both methods have their own advantages and disadvantages. We should select the necessary installation method according to a specific situation.

3.2. Influence of Unbounded Length in the Embedded SMA Beam. In order to study more accurately the influence of unbounded length of internal embedded SMA wires on the self-repairing capacity of beam, the analysis method of controlling crack width in reinforced concrete structures is referred to. According to the bond slip theory, the actual operative length of SMA alloy wires can be expressed as

$$
l=w_{0}+2 \times 20 D+l_{1}
$$

where $D$ is the diameter of SMA wire, $l_{1}$ is the unbounded length of SMA wire, and $w_{0}$ is the length of SMA wire between the surfaces of the crack, as shown in Figure 4.20D is the slip length of the SMA wire at both ends of the crack, which is estimated according to the reinforcement anchorage length ranges from concrete code [10]. where, the effective height of the cross-section of the beam is given by

$$
h_{0}=h-c \text {. }
$$


TABLE 3: Theoretical recovered length of internally embedded SMA alloy wires.

\begin{tabular}{|c|c|c|c|c|c|c|c|}
\hline Beam no. & $w(\mathrm{~mm})$ & $w_{0}(\mathrm{~mm})$ & $D(\mathrm{~mm})$ & $l_{1}(\mathrm{~mm})$ & $l(\mathrm{~mm})$ & $\mathcal{\varepsilon}(\%)$ & $\delta(\mathrm{mm})$ \\
\hline $\mathrm{Al}-1$ & 3.075 & 2.561 & 0.05 & 0 & 22.561 & 5 & 1.128 \\
\hline $\mathrm{Al}-2$ & 2.842 & 2.367 & 0.05 & 10 & 32.367 & 5 & 1.618 \\
\hline $\mathrm{Al}-3$ & 2.975 & 2.478 & 0.05 & 40 & 62.478 & 5 & 3.124 \\
\hline Bl-1 & 2.865 & 2.387 & 0.05 & 0 & 22.387 & 5 & 1.119 \\
\hline Bl-2 & 4.514 & 3.760 & 0.05 & 10 & 33.760 & 5 & 1.688 \\
\hline $\mathrm{Bl}-3$ & 2.681 & 2.233 & 0.05 & 40 & 62.233 & 5 & 3.112 \\
\hline
\end{tabular}

TABLE 4: Experimental and theoretical values of crack recovery.

\begin{tabular}{lccccc}
\hline Beam no. & $\begin{array}{c}\text { Crack width } \\
w(\mathrm{~mm})\end{array}$ & $\begin{array}{c}\text { Experimental value } \\
\text { Values of crack recovery } \\
\Delta w(\mathrm{~mm})\end{array}$ & $\begin{array}{c}\text { Degree of crack recovery } \\
\eta(\%)\end{array}$ & $\begin{array}{c}\text { Theoretical value } \\
\Delta w^{\prime}(\mathrm{mm})\end{array}$ & $\begin{array}{c}\text { Vegree of crack recovery } \\
\eta^{\prime}(\%)\end{array}$ \\
\hline Al-1 & 3.075 & 1.11 & 36.1 & 1.354 & 55.0 \\
Al-2 & 2.842 & 1.828 & 64.3 & 1.943 & 31.6 \\
Al-3 & 2.975 & 2.879 & 96.8 & 1.344 & 100 \\
Bl-1 & 2.865 & 1.123 & 39.2 & 2.026 & 53.1 \\
Bl-2 & 4.514 & 3.25 & 72.0 & 2.681 & 55.1 \\
Bl-3 & 2.681 & 2.617 & 97.6 & 100 \\
\hline
\end{tabular}

According to the proportional relationship in Figure 4,

$$
w_{0}=\frac{h_{0}}{h} w .
$$

By introducing (5) into (6), the following equation can be obtained:

$$
w_{0}=\frac{h-c}{h} w
$$

where $h$ is the height of beam, $c$ is the thickness of the protective layer, and $w$ is the crack width. By introducing (7) into (4), the actual operative length of alloy wire can be obtained when the unbonded length of SMA wire is $l_{1}$ :

$$
l=\frac{h-c}{h} w+2 \times 20 D+l_{1} .
$$

If the strain of SMA wire is $\varepsilon$ and the SMA wire completely recovers its initial shape, the recovery strain is also $\varepsilon$. When the unbounded length of SMA wire is $l_{1}$ and the cracks are completely repaired, the recovered length of alloy wire can be obtained as

$$
\delta=l \varepsilon=\left(\frac{h-c}{h} w+2 \times 20 D+l_{1}\right) \varepsilon .
$$

By substituting the parameters of internally embedded SMA wires beam into (9), we can obtain the value of the theoretically recovered length of SMA wires, as shown in Table 3.

Based on the unbonded length of SMA wires tabulated in Table 3, the experiment study on the self-repair ability of beam cracks was conducted. Figure 5 shows the influence of unbonded length of SMA wires on recovery degree of cracks.
Beams numbered as A1-1, Al-2, and Al-3 are made of the same materials. As can be seen from Figure 5 and Table 3, the longer the unbounded length is, the better the cracks recover. Cracks on beam Al-3 are almost nonvisible. Therefore, the unbonded length of SMA wires in beam Al-3 meets the required length. Similar situations for beams Bl-1, Bl-2, and Bl-3 can be observed, as shown in Figure 5.

However, further study is necessary to verify nontheoretical unbonded length of SMA wires in the beam that meets the required length for repairing cracks. The experimental and theoretical variations of crack width during recovery process are tabulated in Table 4, where the unbonded length in beams A1-1, Al-2 and Al-3 are respectively, $0 \mathrm{~mm}, 10 \mathrm{~mm}$, and $40 \mathrm{~mm}$ and the same in beams B1-1, Bl-2, Bl-3.

As can be seen from Table 4, the experimental and theoretical values of crack recovery in beams with internally embedded SMA wires are in good agreement. Therefore, in order to achieve the self-repair ability, the unbonded length $l_{m}$ in embedded SMA polymer beams must satisfy the relationship $l_{m} \geq l_{1}$. The minimum unbonded length achieving self-repair is given by

$$
l_{m} \geq l_{1}=\frac{\delta}{\varepsilon}-\frac{h-c}{h} w-2 \times 20 D,
$$

where $\delta$ represents the recovered length of SMA wire, $\varepsilon$ is the recovery strain of SMA wire, $h$ is the height of beam, $c$ is the thickness of the protective layer, and $D$ is the diameter of SMA wire.

3.3. Other Factors Affecting Self-Repairing Capability. The material characteristics of the beams also affect the selfrepairing capability. The stiffness of beam Bl-3 made from pouring clays and silicones is small. More energy is needed 
The crack recovery situation of beams made of different materials

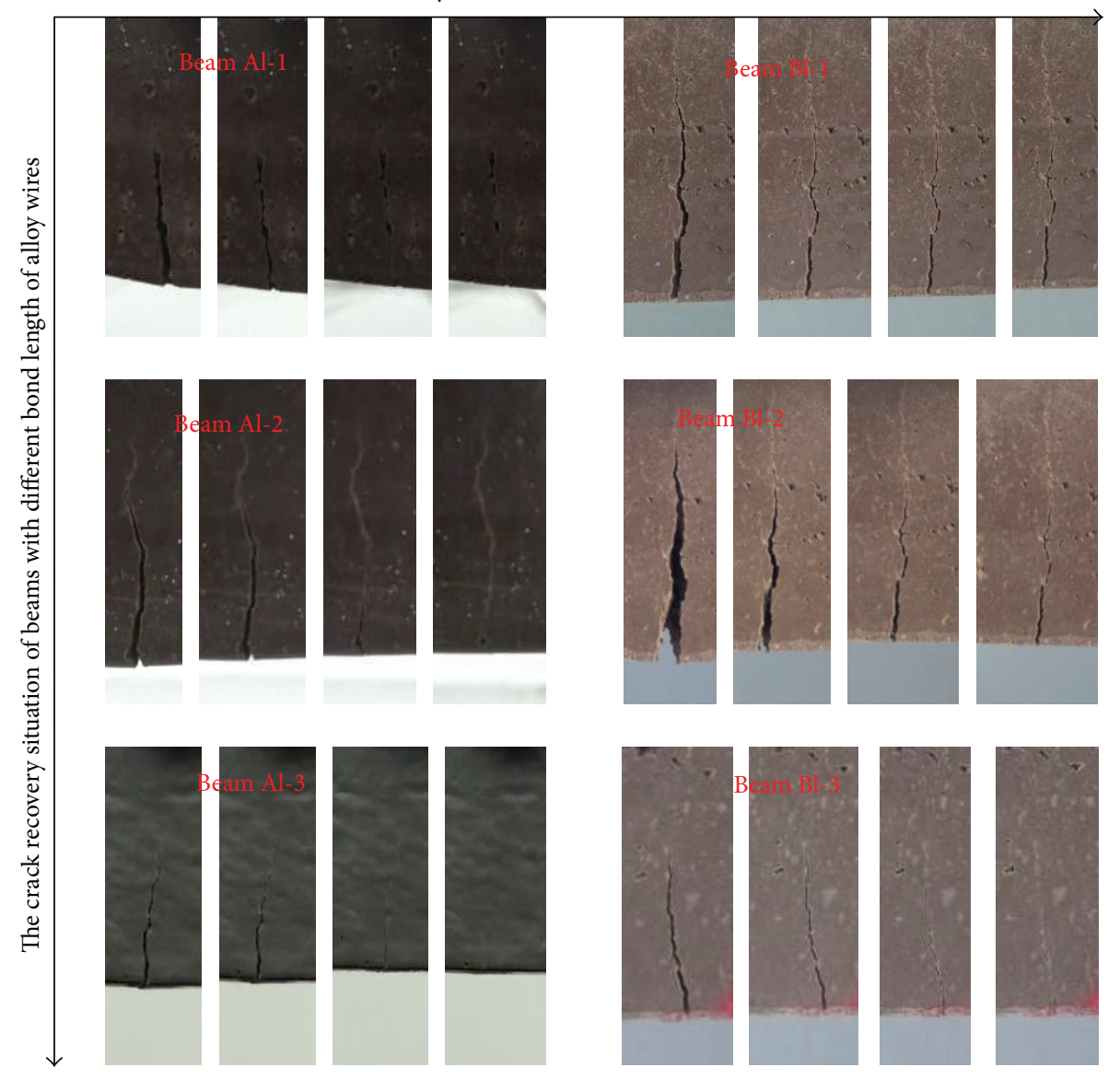

FIGURE 5: Crack recovery situation of beams with internally embedded SMA wires.
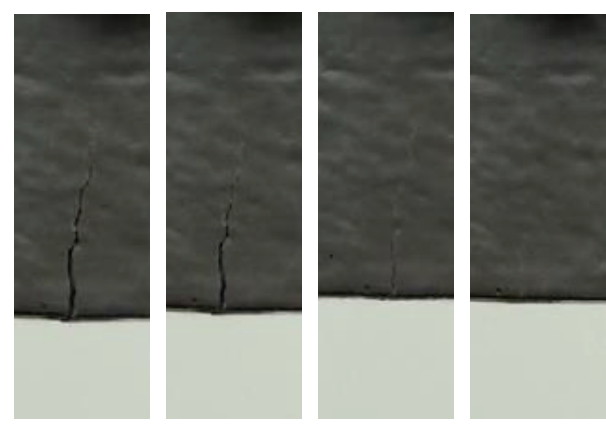

FIGURE 6: Crack closure of beam Al-3.
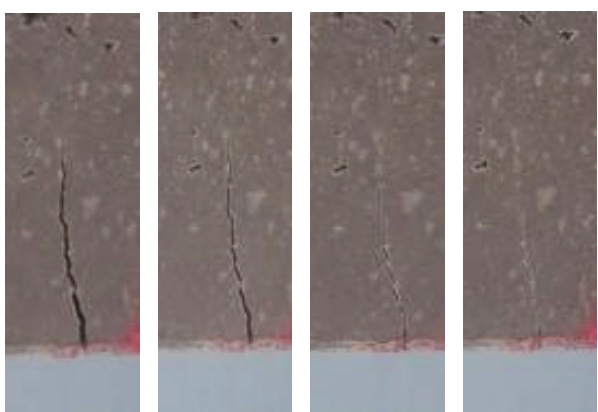

FIgURE 7: Crack closure of beam Bl-3. to recover the deformation. The stiffness of beam Al-3 made from pouring epoxy cements and mortars is large and the energy required for repairing is relatively less. Under the condition of very nearly the same recovery degree in beams Bl-3 and A1-3, as shown in Figure 6 and Figure 7, and the same power-on time, the required current intensity for beam A1-3 is 40 percent less than that for beam B1-3.

The current intensity and the crack closure situation are tabulated in Table 5. As can be seen, the required current intensity for the beam made from silicones and clays is larger than that for the beam made from epoxy resins and cement mortars. Therefore, the material characteristics do not play a decisive role in crack closure of beams, but they have certain influence on it. Repairing efficiency of the beam made from flexible materials is low, and the current intensity must be large enough to achieve full recovery.

The shape memory effect and superelastic characteristics of SMA materials of different types are different, and the bond between bars and sterepsinema with aggregate in the beam is also different. Therefore, the properties of SMA alloy also affect the self-repair ability. In addition, the beam crack slags 
TABLE 5: Current intensity and crack closure degree.

\begin{tabular}{lcccc}
\hline $\begin{array}{l}\text { Beam } \\
\text { no. }\end{array}$ & $\begin{array}{c}\text { Crack } \\
\text { width } w \\
(\mathrm{~mm})\end{array}$ & $\begin{array}{c}\text { Values of } \\
\text { crack recovery } \\
\Delta w(\mathrm{~mm})\end{array}$ & $\begin{array}{c}\text { Degree of } \\
\text { crack recovery } \\
\eta(\%)\end{array}$ & $\begin{array}{c}\text { Current } \\
\text { intensity } I(\mathrm{~A})\end{array}$ \\
\hline $\mathrm{Al}-1$ & 3.075 & 1.11 & 36.1 & 3 \\
$\mathrm{Al}-2$ & 2.842 & 1.828 & 64.3 & 3 \\
$\mathrm{Al}-3$ & 2.975 & 2.879 & 96.8 & 3 \\
$\mathrm{Al}-4$ & 2.212 & 2.186 & 98.8 & 2.8 \\
$\mathrm{Bl}-1$ & 2.865 & 1.123 & 39.2 & 5 \\
$\mathrm{Bl}-2$ & 4.514 & 3.25 & 72.0 & 5 \\
$\mathrm{Bl}-3$ & 2.681 & 2.617 & 97.6 & 5 \\
$\mathrm{Bl}-4$ & 4.012 & 4.005 & 99.8 & 3.5 \\
\hline
\end{tabular}

will be stuck in the cracks and wil hinder crack closure, which also has influence on crack closure.

\section{Conclusion}

In this paper, based on the small stiffness of the composite materials and obvious crack closure phenomenon, the crack closure capacity of beams is theoretically and experimentally analyzed and it can be concluded as follows.

(1) External installation method and internal embedment method are viable in crack closure, and both methods have their own advantages and disadvantages. We should select the appropriate method according to specific conditions.

(2) The minimum unbonded length of the embedded SMA polymer beams that achieve repair is given by (10).

(3) Properties of beam material and SMA affect crack closure. These factors should be avoided or excluded in the repairing process.

\section{Conflict of Interests}

The authors declare that there is no conflict of interests regarding the publication of this paper.

\section{Acknowledgments}

This work has been supported by the National Natural Science Foundation of China (51178277), Program for New Century Excellent Talents in University (NCET-121013), Program for Liaoning Excellent Talents in University (LR2012018), and the Shenyang City Science Foundation of China (F11-163-9-00).

\section{References}

[1] Z.-P. Cao and S.-L. Wang, "Study on application of intelligent material systems and structures to civil engineering," Journal of Chongqing Jianzhu University, vol. 23, no. 1, pp. 1-4, 2001.
[2] Z.-W. Luo, Basic Theoretical Studies on Intelligent Concrete Beams Using Unbonded External SMA Wires, Tongji University, Shanghai, China, 2006.

[3] S.-L. He, X.-Y. Huang, and M.-S. Chen, "The research of shape memory alloy reinforced concrete with self-diagnosis and selfadaptation smart structures," in Proceedings of the Chinese Materials Symposium, pp. 622-625, Industry Press, Beijing, China, 1996.

[4] B.-Q. Tao, Smart Materials Structures, Defense Industry Press, 1997.

[5] A. K. Maji and I. Negret, "Smart prestressing with shapememory alloy," Journal of Engineering Mechanics, vol. 124, no. 10, pp. 1121-1128, 1998.

[6] S. Yan, J. Sun, and W. Wang, "Deformation property of smart concrete continuous beams reinforced with shape memory alloy rebars," Concrete, pp. 8-12, 2010.

[7] H. Li, C. X. Mao, Z. Q. Liu, and J. P. Ou, "Shape memory alloybased smart civil structures with self-sensing and repairing capabilities," in Sensing Issues in Civil Structural Health Monitoring, Chapter 4, pp. 259-268, 2005.

[8] H. Li, Z.-Q. Liu, and J.-P. Ou, "Experimental study of a simple reinforced concrete beam temporarily strengthened by SMA wires followed by permanent strengthening with CFRP plates," Engineering Structures, vol. 30, no. 3, pp. 716-723, 2008.

[9] H. Li, Z.-Q. Liu, and J.-P. Ou, "Study on reinforced concrete beams strengthened using shape memory alloy wires in combination with carbon-fiber-reinforced polymer plates," Smart Materials and Structures, vol. 16, no. 6, pp. 2550-2559, 2007.

[10] D.-J. Ding, Modern Concrete Structures, China Architectural Press, 2000. 


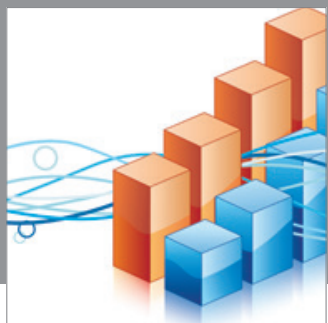

Advances in

Operations Research

mansans

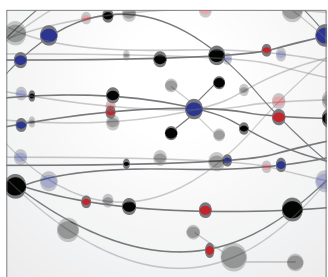

The Scientific World Journal
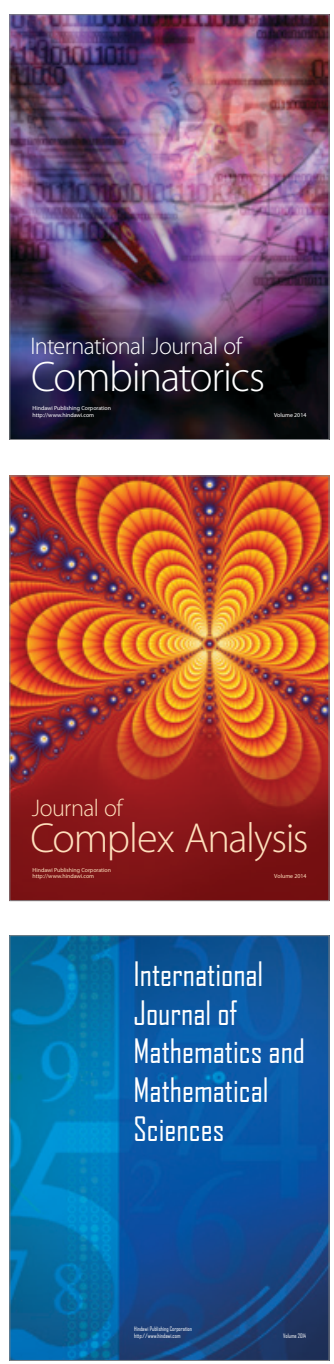
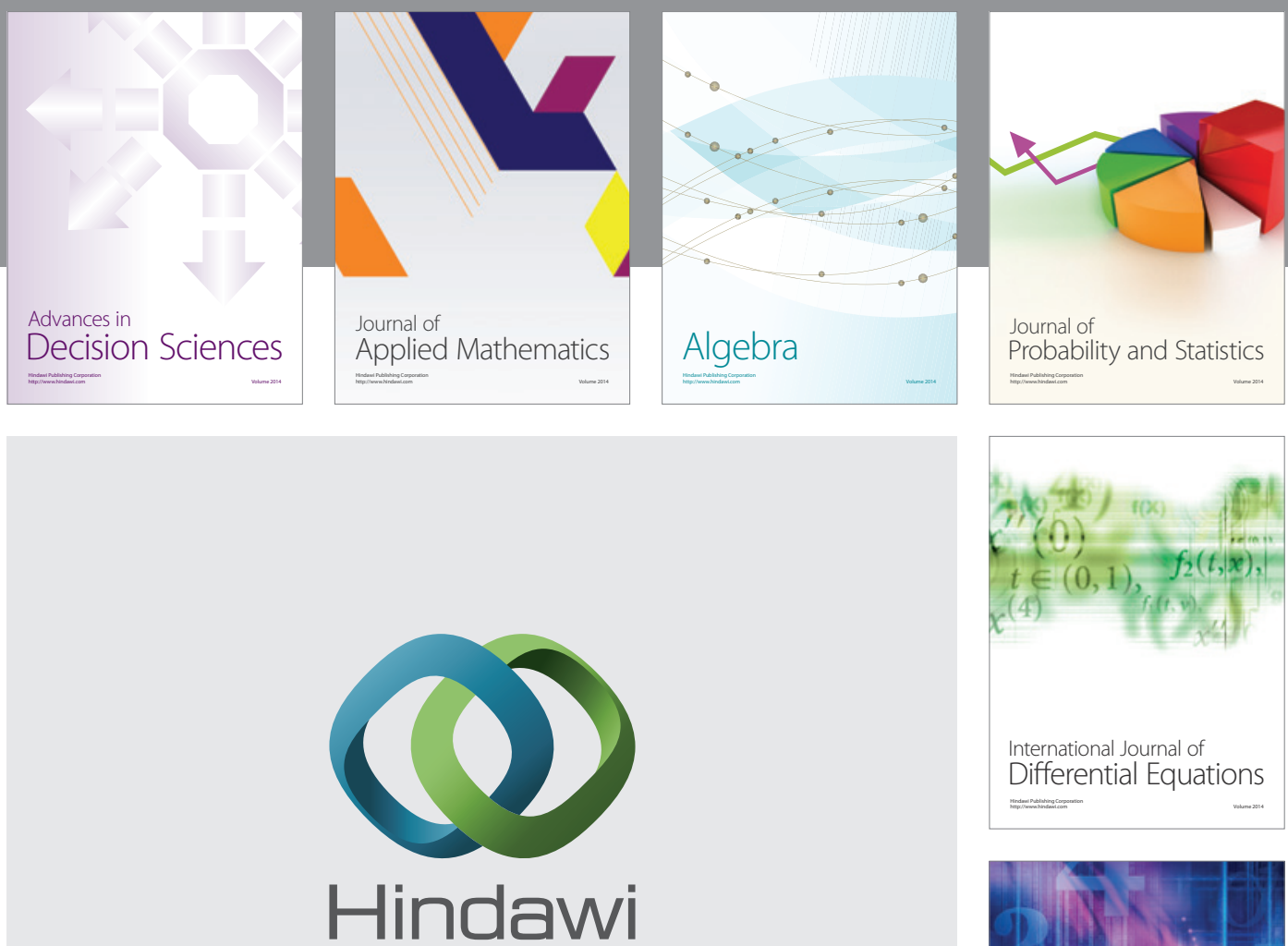

Submit your manuscripts at http://www.hindawi.com
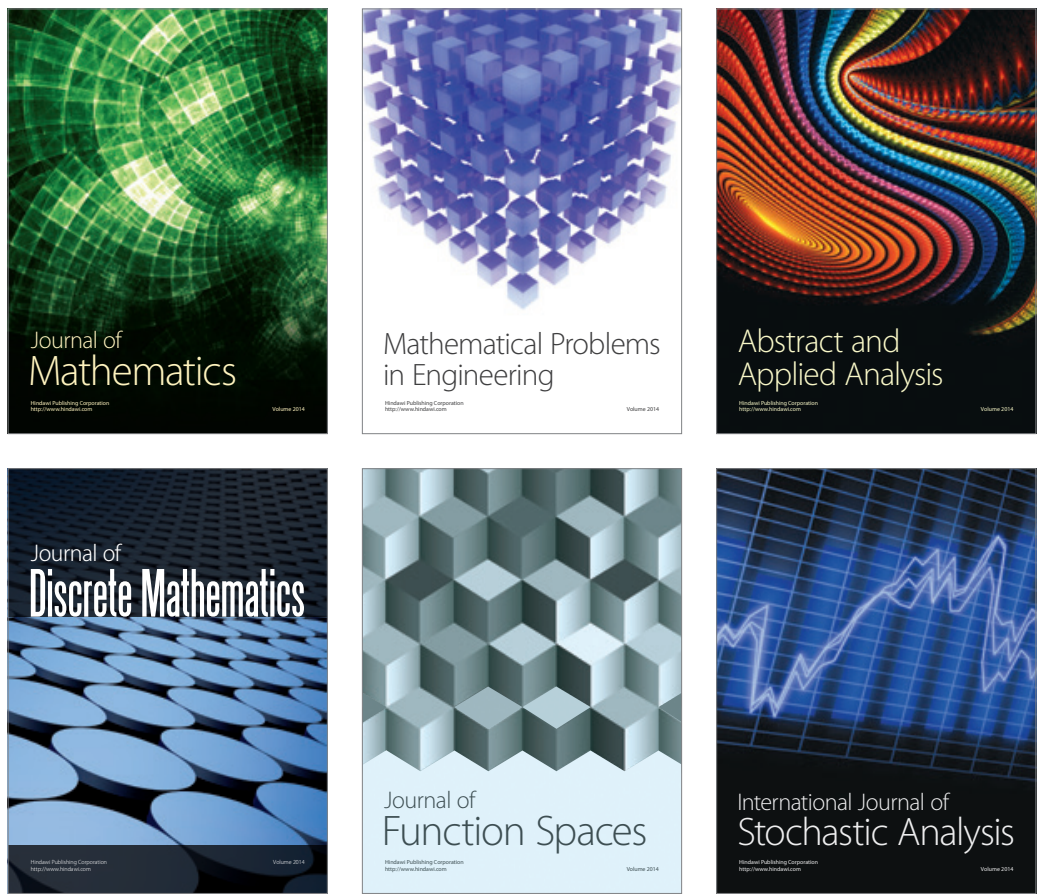

Journal of

Function Spaces

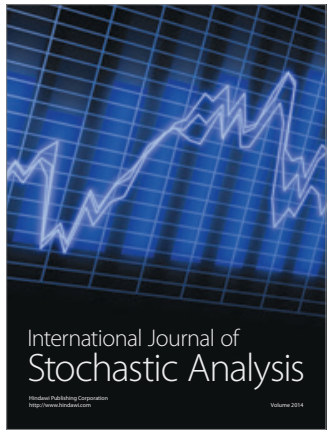

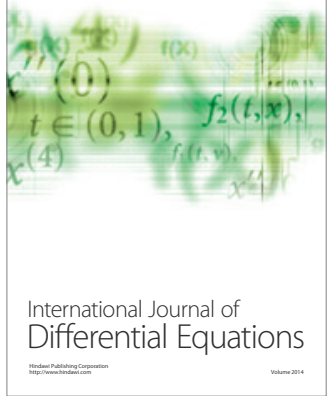
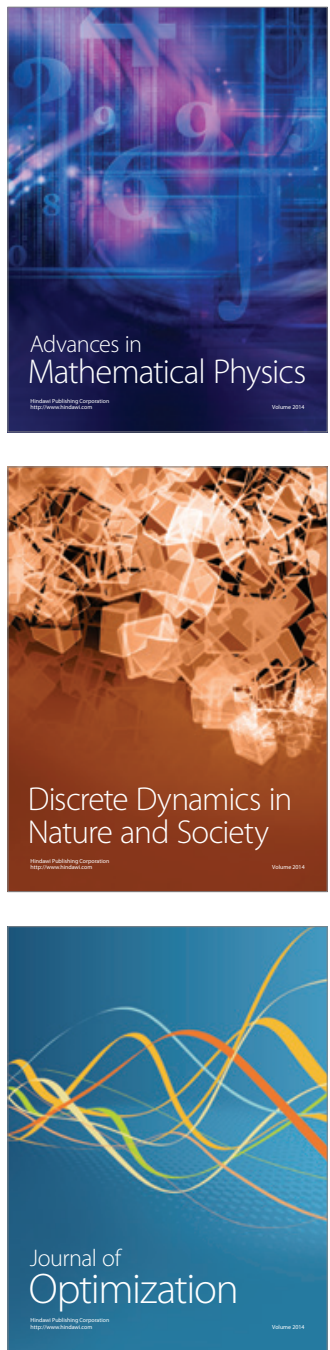